\title{
The Fama-French Five-Factor Model Plus Momentum: Evidence for the German Market
}

\author{
Philipp Dirkx ${ }^{1}$ Franziska J. Peter ${ }^{1}$
}

Received: 13 December 2018 / Accepted: 3 October 2020 / Published online: 23 October 2020

(C) The Author(s) 2020

\begin{abstract}
We implement the Fama-French five-factor model and enhance it with a momentum factor for the German market using recent monthly data from 2002 to 2019. We construct the factors associated with the market, size, value, profitability, investment, and momentum for the CDAX constituents and examine to what extent this six-factor model captures the return premia in the German market. Our preliminary analysis does not document any significant evidence on the profitability or investment premium.

The results on the six-factor model compared with the three-factor model reveal that the additional factors do not add significant explanatory power to the analysis. We conclude that the relevance of the profitability and investment factors within the context of international asset pricing studies cannot be transferred to the countryspecific case of the German market.
\end{abstract}

Keywords Asset pricing · Fama-French five-factor model - German stock market

JEL-Classification G12 - G10

\section{Introduction}

Recently, Fama and French (2015) introduced a five-factor asset pricing model that augments their three-factor model (Fama and French, 1993) by adding the profitability and investment factors. Fama and French (2015) have focused on the U.S. market, while Fama and French (2017) extend the analysis to a global reach, cover-

F. J. Peter

Franziska.Peter@zu.de

1 Zeppelin University, Am Seemooser Horn 20, 88045 Friedrichshafen, Germany 
ing North America, Europe, and Asia Pacific. Country-specific studies, however, are rare, despite the fact that the results in Fama and French (2012), Fama and French (2017), and Griffin (2002) suggest that the global version of the factor asset pricing model is not overall convincing - and that local versions might provide further insights regarding relevant factors. Among previous country-specific studies are those by Daniel et al. (2001), who examine asset pricing anomalies in the Japanese stock market, and L'Her et al. (2004), who apply the Carhart (1997) four-factor model to the Canadian stock market. The Fama-French five-factor model has been tested on the Japanese market by Kubota and Takehara (2018) and on Australian data by Chiah et al. (2016).

However, to the best of our knowledge, a factor model that includes investment and profitability factors has not been implemented for the German stock market. We fill this gap by using recent monthly data of the CDAX constituents from 2002 to 2019 and analyze, whether there exists evidence for an investment or profitability premium. Subsequently, we incorporate these recently introduced factors within a factor model. Because our preliminary analysis hints at the existence of a momentum effect, we also include momentum as an additional factor and empirically examine the validity of the resulting six-factor model for the German stock market. This sixfactor model is also considered by Fama and French (2017), when comparing nested factors models.

The German market has been previously studied by Ziegler et al. (2007), who apply the Fama-French three-factor model to the German equity market and cover a time period from 1968 to 1995 . They conclude that the explanatory power of the three-factor model in Germany is not as high as in the U.S., however, it constitutes an improvement compared with a one-factor model. Schmidt et al. (2019) show within the context of a broad international study that the German equity market had a significant negative size premium between 1991 and 2012. Glaser and Weber (2003) analyse the momentum effect in the German market, and Hanauer et al. (2011) apply the Carhart four-factor model to the German equity market by relying on a sample covering the period 1996 until 2011. They summarize that the fourfactor model yields a slight improvement over the three-factor model and that the factors for the German market show little correlation to other international studies. Artmann et al. (2012) conduct an analysis on the German equity market, covering the one-, three-, and four-factor model. They analyze the period from 1960 until 2006 and conclude that the results are sensitive to the construction and sorting procedures of the portfolios. The investment premium is studied extensively by Walkshaeusl and Lobe (2014), who use a large sample of countries, including Germany. Their results provide some evidence for an investment premium; however, this finding is mostly limited to small stocks.

The current paper proceeds as follows: Section 2 introduces the data, and Section 3 conducts preliminary analyses on potential profitability and investment premiums, including Fama-MacBeth regressions. Section 4 applies the three- and six-factor model to the German stock market, and Section 5 concludes the paper. 


\section{Data}

We rely on monthly returns of the CDAX constituents, covering a time period of 17 years, ranging from June 2002 to June 2019. The data are from the Bloomberg database. We follow previous asset pricing studies by Fama and French (2015), Ziegler et al. (2007), Hanauer et al. (2011), and Artmann et al. (2012) and exclude financials from our data base.

The CDAX includes all stocks traded on the Frankfurt Stock Exchange that are listed in the general standard or prime standard market segments. Portfolios sorted according to the factors outlined in the following sections are recalculated at the end of June every year. Only companies that have a positive book equity value are used. The total return comprises the price return of a stock and the reinvested dividend. When applying all the filters necessary to calculate all six factors, the average number of analyzed stocks excluding financials is 317 , while the number of stocks never drops below 264. Details on our filters can be found in Table 12 in the appendix. The variables used for the construction of the profitability and investment measures and the corresponding Bloomberg codes are outlined in Appendix 1.

The smaller amount of available entities compared with the U.S. market leads to the adjustment of calculating $16(4 \times 4)$ value-weighted portfolios rather than 25 (5x5), as in Fama and French (2015). This corresponds to the previous studies of the German equity market by Artmann et al. (2012) and Hanauer et al. (2011).

The correlation of the returns of the adjusted investment universe with the CDAX returns amounts to 0.98 . Consequently, we assume that our sample is representative of the overall German equity market. The basket of securities that remain in the sample after applying all filters constitutes the proxy for the market portfolio for our regressions. The risk-free rate is based on the one month EURIBOR rates.

\section{Profitability and investment premia}

Although researchers have identified numerous factors over the last 50 years (e.g., Banz, 1981 and Harvey et al., 2016), Fama and French justify the identification of their additional two factors by relying on the dividend discount model (i.e., Miller and Modigliani, 1961) to derive the profitability and investment factor. Based on the dividend discount model, the present value of a stock, $m_{t}$, at time $t$ is given by the discounted, expected dividend

$$
m_{t}=\sum_{\tau=1}^{\infty} \frac{E\left(d_{t+\tau}\right)}{(1+r)^{\tau}}
$$

where $E\left(d_{t+\tau}\right)$ denotes the expected dividend per share for period $t+\tau$ and $r$ denotes the long-term expected internal rate of return on an investment in this stock. Fama and French (2015) slightly adjust Equation (1) to show the relationship between the expected return, expected profitability, expected investment, and the book-to-market 
ratio. In particular, they show that the total market value, $m_{t}$, of a stock at time $t$ is equal to

$$
m_{t}=\sum_{\tau=1}^{\infty} \frac{E\left(Y_{t+\tau}-d B_{t+\tau}\right)}{(1+r)^{\tau}}
$$

where $Y_{t+\tau}$ denotes the total equity earnings for period $t+\tau$ and $d B_{t+\tau}$ gives the delta of the book value between $t+\tau$ and $t+\tau-1$. Subsequently, they divide the whole term by the book value in time $t, B_{t}$

$$
\frac{m_{t}}{B_{t}}=\frac{\sum_{\tau=1}^{\infty} E\left(Y_{t+\tau}-d B_{t+\tau}\right) /(1+r)^{\tau}}{B_{t}} .
$$

Equation (3) implies that, ceteris paribus, a) a higher book-to-market ratio implies a higher expected return; b) higher expected earnings (profitability) imply a higher expected return; and c) the higher the growth in book equity (investment), the lower the expected return.

To examine the empirical prevalence of the profitability and investment effect in the German market, we analyze single-sorted portfolios and conduct Fama-MacBeth regressions. The operating profitability (OP) according to Fama and French (2015) is calculated using all accounting numbers from the end of the previous fiscal year. It is defined by the annual revenues minus the cost of goods sold, interest expenses, selling, general, and administrative expenses divided by the book equity. Investment (INV) according to Fama and French (2015) is defined as the ratio of total assets of a stock at the fiscal year end of $t-1$ and the total assets at fiscal year end of $t-2$. For details on the variable construction and sample filters, compare Appendix 1. Furthermore, we consider a sample excluding micro caps (w/o Micro Cap) following Ball et al. (2015), and a sample consisting of micro caps (Micro Cap) only. We define micro caps as the stocks associated with a market capitalization below the 20th (20) or alternatively below the 30th percentile (30) of the full sample market capitalization distribution. This implies that micro caps are identified based on the whole sampling period and subsequently are either classified as micro cap or nonmicro cap during all years under consideration. Table 1 presents the average value weighted excess returns of five single-sorted portfolios. The portfolio excess returns are sorted column-wise ranging from the lowest to the highest quintile.

In contrast to the previous results by Fama and French (2015), we cannot document a profitability premium based on the single-sorted portfolios. Regarding investment-sorted portfolio returns, Table 1 reveals lower returns on the highest quintile compared with the lowest quintile; however, there is no clear decreasing pattern when considering the other quintiles. Our descriptives also do not indicate a significant impact of excluding micro caps; however, we observe a decreasing pattern for returns sorted by investment quintiles when considering only micro caps. This supports the argument by Walkshaeusl and Lobe (2014), who mention that micro caps might drive the results when considering equally weighted portfolios.

Switching to the double-sorted portfolios, Table 2 shows excess returns for valueweighted portfolios based on $4 \times 4$ independent sorts of the corresponding two vari- 
Table 1 Returns of single-sorted profitability and investment portfolios. The table reports the excess average returns to portfolios based on potential profitability (OP) and investment (INV) effects. The portfolio excess returns are sorted column-wise ranging from the lowest to the highest quintile. Standard errors are given in parentheses

\begin{tabular}{|c|c|c|c|c|c|}
\hline$\overline{\mathbf{O P}}$ & Low & 2 & 3 & 4 & High \\
\hline \multirow[t]{2}{*}{ All } & 0.91 & 0.79 & 0.88 & 0.76 & 0.70 \\
\hline & $(0.17)$ & $(0.13)$ & $(0.13)$ & $(0.13)$ & $(0.11)$ \\
\hline \multirow{2}{*}{$\begin{array}{l}\text { w/o Micro } \\
\text { Cap (20) }\end{array}$} & 0.69 & 0.63 & 0.75 & 0.80 & 0.66 \\
\hline & $(0.13)$ & $(0.10)$ & $(0.11)$ & $(0.12)$ & $(0.11)$ \\
\hline \multirow{2}{*}{$\begin{array}{l}\text { w/o Micro } \\
\text { Cap (30) }\end{array}$} & 0.82 & 0.63 & 0.72 & 0.83 & 0.70 \\
\hline & $(0.12)$ & $(0.10)$ & $(0.11)$ & $(0.11)$ & $(0.11)$ \\
\hline \multirow{2}{*}{$\begin{array}{l}\text { Only Micro } \\
\text { Cap (20) }\end{array}$} & 1.39 & 0.78 & 1.86 & 0.94 & 1.15 \\
\hline & $(0.28)$ & $(0.19)$ & $(0.21)$ & $(0.18)$ & $(0.19)$ \\
\hline \multirow{2}{*}{$\begin{array}{l}\text { Only Micro } \\
\text { Cap (30) }\end{array}$} & 0.95 & 0.88 & 1.53 & 0.91 & 0.57 \\
\hline & $(0.25)$ & $(0.18)$ & $(0.18)$ & $(0.16)$ & $(0.17)$ \\
\hline INV & Low & 2 & 3 & 4 & High \\
\hline \multirow[t]{2}{*}{ All } & 1.32 & 0.98 & 0.72 & 0.87 & 0.19 \\
\hline & $(0.15)$ & $(0.11)$ & $(0.09)$ & $(0.09)$ & $(0.11)$ \\
\hline \multirow{2}{*}{$\begin{array}{l}\text { w/o Micro } \\
\text { Cap (20) }\end{array}$} & 0.84 & 0.77 & 0.80 & 0.87 & 0.27 \\
\hline & $(0.13)$ & $(0.10)$ & $(0.10)$ & $(0.09)$ & $(0.12)$ \\
\hline \multirow{2}{*}{$\begin{array}{l}\text { w/o Micro } \\
\text { Cap (30) }\end{array}$} & 0.99 & 0.75 & 0.93 & 0.81 & 0.26 \\
\hline & $(0.13)$ & $(0.11)$ & $(0.10)$ & $(0.10)$ & $(0.12)$ \\
\hline \multirow{2}{*}{$\begin{array}{l}\text { Only Micro } \\
\text { Cap (20) }\end{array}$} & 2.24 & 2.00 & 1.24 & 1.02 & -0.26 \\
\hline & $(0.42)$ & $(0.34)$ & $(0.33)$ & $(0.30)$ & $(0.32)$ \\
\hline \multirow{2}{*}{$\begin{array}{l}\text { Only Micro } \\
\text { Cap (30) }\end{array}$} & 1.96 & 1.30 & 0.95 & 0.55 & 0.12 \\
\hline & $(0.33)$ & $(0.27)$ & $(0.24)$ & $(0.22)$ & $(0.23)$ \\
\hline
\end{tabular}

ables. The rows refers to the size quartile, while the columns refer to the valuation $(\mathrm{BM})$, the profitability (OP), or the investment (Inv) quartile.

For small stocks, the average excess return of the portfolios tend to increase with a rising book-to-market ratio. In contrast to the findings in previous studies that use international data, there is no clear pattern regarding market capitalization. The relationship between $\mathrm{B} / \mathrm{M}$, size, and excess returns in the German market is in line with the findings of Schrimpf et al. (2007), Hanauer et al. (2011), and Artmann et al. (2012). Within the international study of Fama and French (2017), it is also detected that the size effect in Europe for the size-B/M-sorted portfolios is not existent and only weak in North America for the period of 1990 to 2015.

Considering the size/OP portfolios in the second panel of Table 2, we do not observe a clear pattern of decreasing average returns with size. This finding does not support those of Fama and French (2015), who report their size/OP portfolios of 
Table 2 Returns on double-sorted portfolios. The table shows average monthly excess returns and t-statistics on size-book-to-market (Size/BM), size-investment (Size/Inv), and size-profitability (Size/OP) double-sorted (4x4) value-weighted portfolios for June 2002 until June 2019

\begin{tabular}{llllllllll}
\hline Average returns & \multicolumn{7}{c}{ T-statistic } \\
\hline Size/BM & Low & 2 & 3 & High & Size/BM & Low & 2 & 3 & High \\
\hline Small & 0.17 & 0.59 & 0.83 & 0.95 & Small & 0.59 & 2.04 & 2.84 & 2.93 \\
2 & 0.73 & 0.46 & 1.00 & 0.49 & 2 & 1.83 & 1.76 & 3.10 & 1.60 \\
3 & 0.45 & 0.86 & 0.82 & 0.78 & 3 & 1.71 & 3.01 & 2.62 & 2.14 \\
Big & 0.61 & 0.50 & 0.94 & 0.77 & Big & 1.81 & 1.69 & 2.62 & 1.82 \\
\hline Size/OP & Low & 2 & 3 & High & Size/OP & Low & 2 & 3 & High \\
\hline Small & 0.40 & 0.46 & 0.98 & 0.72 & Small & 1.31 & 1.72 & 3.37 & 1.88 \\
2 & 0.77 & 0.84 & 0.74 & 0.64 & 2 & 2.37 & 3.19 & 2.43 & 2.11 \\
3 & 1.08 & 0.53 & 1.16 & 0.90 & 3 & 2.87 & 1.69 & 3.56 & 2.70 \\
Big & -0.26 & 0.82 & 0.93 & 0.69 & Big & -0.33 & 2.70 & 2.56 & 2.09 \\
\hline Size/Inv & Low & 2 & 3 & High & Size/Inv & Low & 2 & 3 & High \\
\hline Small & 0.57 & 0.53 & 0.91 & 0.59 & Small & 1.68 & 1.67 & 2.69 & 1.88 \\
2 & 0.48 & 0.82 & 0.90 & 0.69 & 2 & 1.56 & 3.19 & 2.99 & 1.98 \\
3 & 1.39 & 1.00 & 0.90 & 0.81 & 3 & 3.46 & 3.36 & 3.03 & 2.20 \\
Big & -0.27 & 0.25 & 1.07 & 0.50 & Big & -0.32 & 1.00 & 3.06 & 1.54 \\
\hline & & & & & & & & &
\end{tabular}

U.S. stocks as showing a size effect across all OP quintiles, while excess returns are steadily increasing with a higher operating profitability. In their international study, Fama and French (2017) find a consistent increase in returns for higher operating profitability across all size quintiles for Europe. Regarding the size-investmentsorted portfolios, Table 2 reveals no clear relationship between increasing or decreasing investment and average excess returns. Fama and French (2015) find a size effect in four out of five size-investment-sorted quintiles and decreasing returns with increasing investment across all size quintiles. Fama and French (2017) report similar patterns for returns to size-investment-sorted portfolios for Europe. ${ }^{1}$

Following Novy-Marx (2013), we conduct firm-level Fama-MacBeth regressions to further analyze the existence of a profitability or investment premium.

Table 3 shows the results. Considering Panel A, we observe a marginally significant effect for operating profitability only for the sample when excluding micro caps at the 30th percentile (w/o Micro 30). The results for the samples including micro caps only show positive but insignificant coefficients for operating profitability. Similar conclusions could be drawn from the regressions when considering investment (Panel B). All estimates are insignificant, showing no indication for an investment premium. The same conclusion holds for Panel C, where profitability and investment coefficients are insignificant. Our results on negative and insignificant coefficients on market beta and the strongly significant effects of lagged returns correspond to the findings by Artmann et al. (2012). Consequently, there is evidence for the existence of a momentum effect, and we will implement the five-factor model including

\footnotetext{
${ }^{1}$ Considering triple-sorted portfolios in Table 13, we cannot report any evidence for a profitability or investment premium.
} 
Table 3 Fama-MacBeth regressions. The table reports the results on firm-level Fama-MacBeth regressions based on monthly returns. $O P$ and $I N V$ denote the operating profitability and investment as defined in Fama and French (2015), Bet $a$ denotes the market beta from firm level time series regressions using the full sample and the CDAX as the market proxy. $\log (B / M)$ gives the log book-to-market ratio, $\log (M C)$ the $\log$ market capitalization, $r_{0,1}$ gives the previous period returns, and $r_{2,12}$ denote the returns during the previous 12 months, excluding $r_{0,1}$. Panel A gives the results, including $O P$, Panel B includes $I N V$, and Panel $\mathrm{C}$ includes $O P$ and $I N V$ as explanatory variables. The columns show results for the full sample, excluding micro caps (w/o Micro) and micro caps only (Micro). T-statistics are given in parenthesis and are based on Newey-West standard errors

\begin{tabular}{|c|c|c|c|c|c|}
\hline \multicolumn{6}{|l|}{ Panel A } \\
\hline & All & w/o Micro 20 & w/o Micro 30 & Micro 20 & Micro 30 \\
\hline \multirow[t]{2}{*}{$\overline{\mathrm{C}}$} & -0.25 & -0.49 & -0.15 & 2.31 & 5.72 \\
\hline & $(-0.33)$ & $(-0.59)$ & $(0.53)$ & $(0.36)$ & (1.69) \\
\hline \multirow[t]{2}{*}{ OP } & 0.02 & 0.02 & 0.04 & 0.07 & 0.03 \\
\hline & $(0.99)$ & $(1.16)$ & $(1.73)$ & $(1.34)$ & $(0.75)$ \\
\hline \multirow[t]{2}{*}{ Beta } & -0.18 & -0.10 & -0.08 & -0.09 & -0.91 \\
\hline & $(-0.38)$ & $(-0.21)$ & $(-0.19)$ & $(-0.12)$ & $(-1.18)$ \\
\hline \multirow[t]{2}{*}{$\log (\mathrm{B} / \mathrm{M})$} & -0.07 & -0.01 & 0.03 & -0.58 & -0.44 \\
\hline & $(-0.71)$ & $(-0.05)$ & $(0.37)$ & $(-2.21)$ & $(-1.83)$ \\
\hline \multirow[t]{2}{*}{$\log (\mathrm{MC})$} & 0.05 & 0.06 & 0.05 & -0.10 & -0.23 \\
\hline & $(1.35)$ & $(1.60)$ & $(1.23)$ & $(-0.24)$ & $(-1.38)$ \\
\hline \multirow[t]{2}{*}{$r_{0,1}$} & -0.02 & -0.01 & -0.01 & -0.04 & -0.03 \\
\hline & $(-1.35)$ & $(-1.14)$ & $(-0.71)$ & $(-2.62)$ & $(-2.56)$ \\
\hline \multirow[t]{2}{*}{$r_{2,12}$} & 0.02 & 0.02 & 0.02 & 0.02 & 0.02 \\
\hline & $(6.82)$ & $(7.41)$ & $(6.51)$ & $(3.41)$ & (3.36) \\
\hline \multicolumn{6}{|l|}{ Panel B } \\
\hline & All & w/o Micro 20 & w/o Micro 30 & Micro 20 & Micro 30 \\
\hline \multirow[t]{2}{*}{$\overline{\mathrm{C}}$} & -0.52 & -0.64 & -0.37 & -0.04 & 4.54 \\
\hline & $(-0.66)$ & $(-0.80)$ & $(-0.45)$ & $(-0.01)$ & (1.34) \\
\hline \multirow[t]{2}{*}{ INV } & 0.11 & -0.03 & -0.25 & 0.67 & 1.44 \\
\hline & $(0.49)$ & $(-0.12)$ & $(-0.61)$ & (1.09) & $(1.70)$ \\
\hline \multirow[t]{2}{*}{ Beta } & -0.11 & -0.11 & -0.07 & 0.01 & -1.02 \\
\hline & $(-0.38)$ & $(-0.24)$ & $(-0.15)$ & $(0.02)$ & $(-1.38)$ \\
\hline \multirow[t]{2}{*}{$\log (\mathrm{B} / \mathrm{M})$} & -0.03 & 0.01 & 0.03 & -0.13 & -0.24 \\
\hline & $(-0.10)$ & $(1.84)$ & $(0.32)$ & $(-0.58)$ & $(-1.07)$ \\
\hline \multirow[t]{2}{*}{$\log (\mathrm{MC})$} & 0.06 & 0.03 & 0.05 & 0.04 & -0.21 \\
\hline & $(-0.55)$ & (1.67) & $(1.42)$ & $(0.10)$ & $(-1.06)$ \\
\hline \multirow[t]{2}{*}{$r_{0,1}$} & -0.02 & -0.01 & -0.01 & -0.04 & -0.03 \\
\hline & $(-1.35)$ & $(-1.12)$ & $(-0.62)$ & $(-2.46)$ & $(-3.29)$ \\
\hline \multirow[t]{2}{*}{$r_{2,12}$} & 0.02 & 0.02 & 0.02 & 0.02 & 0.02 \\
\hline & (7.25) & $(7.76)$ & $(6.71)$ & $(2.80)$ & (4.07) \\
\hline
\end{tabular}


Table 3 (Continued)

\begin{tabular}{llllll}
\hline Panel C & All & w/o Micro 20 & w/o Micro 30 & Micro 20 & Micro 30 \\
\hline C & -0.24 & -0.48 & -0.13 & 2.94 & 6.77 \\
\multirow{2}{*}{ INV } & $(-0.32)$ & $(-0.59)$ & $(-0.16)$ & $(0.44)$ & $(2.10)$ \\
& 0.07 & -0.08 & -0.23 & 0.42 & 1.27 \\
OP & $(0.35)$ & $(-0.38)$ & $(-1.02)$ & $(0.63)$ & $(1.59)$ \\
& 0.02 & 0.02 & 0.03 & 0.07 & 0.02 \\
Beta & $(0.99)$ & $(1.15)$ & $(1.74)$ & $(1.15)$ & $(0.42)$ \\
& -0.18 & -0.09 & -0.06 & 0.14 & -0.86 \\
$\log (\mathrm{B} / \mathrm{M})$ & $(-0.38)$ & $(-0.19)$ & $(-0.14)$ & $(0.17)$ & $(-1.15)$ \\
& -0.07 & -0.01 & 0.02 & -0.58 & -0.44 \\
$\log (\mathrm{MC})$ & $(-0.78)$ & $(-0.05)$ & $(0.20)$ & $(-2.16)$ & $(-1.90)$ \\
& 0.05 & 0.06 & 0.02 & -0.13 & -0.34 \\
$r_{0,1}$ & $(1.34)$ & $(1.62)$ & $(1.21)$ & $(-0.33)$ & $(-1.79)$ \\
& -0.01 & -0.02 & -0.01 & -0.04 & -0.03 \\
$r_{2,12}$ & $(-1.92)$ & $(-1.15)$ & $(-0.72)$ & $(-1.99)$ & $(-2.90)$ \\
& 0.02 & 0.02 & 0.02 & 0.02 & 0.02 \\
& $(6.97)$ & $(7.73)$ & $(6.68)$ & $(3.21)$ & $(3.75)$
\end{tabular}

momentum as an additional factor. Subsequently, we compare this six-factor model to the three-factor model to reach a conclusion as to whether there exists any value added, when using a factor model enhanced by the recently introduced investment and profitability factors.

\section{Implementing a six-factor model for the German market}

\subsection{Factor construction and preliminary results}

Fama and French (2015) add two additional factors to the Fama-French three-factor model and propose a five-factor model. Motivated by the results from our FamaMacBeth regressions, we additionally add a momentum factor, resulting in the following six-factor model:

$$
\begin{aligned}
R_{i t} & =a_{i}+b_{i} R M R F_{t}+s_{i} S M B_{t} \\
& +h_{i} H M L_{t}+r_{i} R M W_{t}+c_{i} C M A_{t}+m_{i} M O M_{t}+\varepsilon_{i t}
\end{aligned}
$$

where $R_{i t}$ denotes the excess return of portfolio $i$ at time $t . R M R F_{t}$ gives the excess return of the market return over the risk-free rate at time $t . S M B_{t}$ relates to the size factor, which is based on the difference between the return of a portfolio of small stocks minus the return of a portfolio consisting of large stocks. The value factor is captured by $H M L_{t}$, where the return difference between a portfolio with a high book-to-market $(\mathrm{B} / \mathrm{M})$ ratio and a portfolio with a low $\mathrm{B} / \mathrm{M}$ ratio is taken. The first newly introduced factor, $R M W_{t}$, captures the potential profitability 
Table 4 Descriptive statistics and correlations for the constructed factors. R (market) denotes the market return constructed from the sample stocks, and $\mathrm{R}$ (risk free) denotes the risk-free rate

\begin{tabular}{lllllll}
\hline & Variable & Mean & St.Dev. & T-Test & \\
& $\begin{array}{l}\text { R (mar- } \\
\text { ket) }\end{array}$ & 0.86 & 5.17 & 2.13 & \\
& $\begin{array}{l}\text { R (risk } \\
\text { free) }\end{array}$ & 0.12 & 0.12 & 11.60 & \\
& RMRF & 0.74 & 5.19 & 1.84 & \\
& SMB & -0.04 & 3.47 & -0.36 & \\
& HML & 0.31 & 2.93 & 1.35 & \\
& RMW & 0.20 & 2.70 & 1.15 & \\
& CMA & 0.15 & 2.76 & 1.02 & \\
& MOM & 0.71 & 3.94 & 2.77 & \\
\hline & & & Correlations & & & \\
& RMRF & SMB & HML & RMW & CMA \\
RMRF & 1 & & & & & \\
SMB & -0.56 & 1 & & & & \\
HML & 0.22 & -0.20 & 1 & & \\
RMW & 0.14 & -0.24 & -0.06 & 1 & \\
CMA & -0.28 & 0.21 & 0.29 & -0.21 & 1 & \\
MOM & -0.19 & 0.07 & -0.17 & 0.24 & 0.11 & 1 \\
\hline
\end{tabular}

premium and is calculated as the return difference of two portfolios, which refer to high profitability and low profitability companies. The second newly introduced investment factor, $C M A_{t}$, measures the difference between the return of a portfolio of stocks with a low investment and the return of a portfolio consisting of stocks with a high investment, while $M O M_{t}$ refers to winners and losers with respect to past performance.

The risk factors are calculated as defined by Fama and French (2015) and can be described as independent $2 \times 3$ sorts. All factors are based on two size groups and three groups for the other sorting variables. The size breakpoint of all factors is the median market capitalization of the sample companies. Concerning the valuation $(\mathrm{B} / \mathrm{M})$, operating profitability (OP), and investment (Inv) factors, the breakpoints are determined by the 30th and 70th quantiles of the sample companies. Details are given in Appendix 2.

Considering the constructed factors, Table 4 provides an overview of the descriptive statistics of the six factors and their correlations. The average return for the SMB factor is $-0.04 \%$, showing no statistical significance. This is coherent with other studies on the German market, yet is not in line with Banz (1981) and the results from international asset pricing studies, which claim that small capitalized companies outperform large capitalized companies. Covering the German market, Schrimpf et al. (2007) calculate a SMB factor average return of $-0.19 \%$ per month between 1969 and 2002. This result is almost identical to the study of Artmann et al. (2012), with an average SMB return of $-0.18 \%$ for the period between 1962 and 2006. Interestingly, Ziegler et al. (2007) cover a slightly shorter period from 1968 to 1995 and report an average return for the SMB factor of $0.08 \%$. In contrast, Hanauer 
et al. (2011) cover the period from 1996 until 2011 and find a strongly negative SMB average return of $-0.71 \%$. This leads to the observation that small companies seem to have performed particularly bad compared with large companies in the end of the 1990s and 2000s. In an international context, the SMB factor of Fama and French (2015) between 1963 and 2012 is significantly positive, with an average return of $0.29 \%$ and a test statistic of 2.24. However, in their international study (2017), none of the regions shows a statistically significant positive or negative SMB factor.

Our RMW factor has an average return of $0.20 \%$ while not being statistically significant. Fama and French $(2015,2017)$ report statistically significant RMW factors with average returns of $0.26 \%$ to $0.40 \%$ for the U.S. and Europe, while Japan and Asia Pacific have average RMW returns of $0.12 \%$ and $0.20 \%$, respectively. The average return for the CMA factor is only $0.15 \%$ with a high standard deviation and low statistical significance. In comparison, only Japan has weaker average returns for the CMA factor with $0.09 \%$ per month, while the U.S., Europe, and Asia Pacific have average returns between $0.22 \%$ and $0.39 \%$ (Fama and French, 2017). The momentum factor shows the highest return after the market factor, which is also statistically significant. This result corresponds to the findings by Hanauer et al. (2011), who report an average return of $1.13 \%$ for their sample of German firms.

In terms of correlation it is worth highlighting that the market factor, RMRF, is negatively correlated to SMB $(-0.56)$, while the SMB factor is negatively correlated to the HML $(-0.20)$ and the RMW (-0.24) factor. A positive correlation exists between the average returns of SMB and CMA (0.21). For the U.S., Fama and French (2015) find that the market factor is only positively correlated to the SMB factor and negatively correlated to all other factors, which is contrary to our results for Germany. Some of these differences might be attributed to the observed inverse size effect in the German market compared with the U.S. market.

Figure 1 shows a graphical depiction of the development of the factors over time. The momentum factor increases continuously after 2009, as does the market factor. However, the market factor exhibits a higher variation. The HML factor performs strongly until the end of 2011, continuously generating negative returns afterwards. On the contrary, the SMB factor underperforms until the end of 2014 and continuously gains in value afterwards. The RMW factor underperformed until the beginning/middle of 2007, basically shortly before the start of the financial crisis, and recovers afterwards. The CMA factor shows a continuous gain until the end of 2011 and drifts downward afterwards, while the MOM factor tends to increase continuously, deviating from this upward path only during the 2008/2009 financial crisis. Although we compare our results to other studies covering the German equity market, these comparisons need to be taken with a grain of salt. Brueckner et al. (2015a) reveal that results for the same analysis period can differ based on the data provider, mainly because of data quality. Hanauer et al. (2011) also offer a depiction of the development of the factors, ranging from July 1996 until December 2011. The development of their SMB and HML factor match the factor performance in Figure 1 pretty well, accounting for the different time horizons. Their HML factor continuously increases between the beginning of the 2000s until the end of their study in 2011, and their SMB factor stagnates between the beginning and middle of the 2000s and then underperforms after that until the end of 2011. 


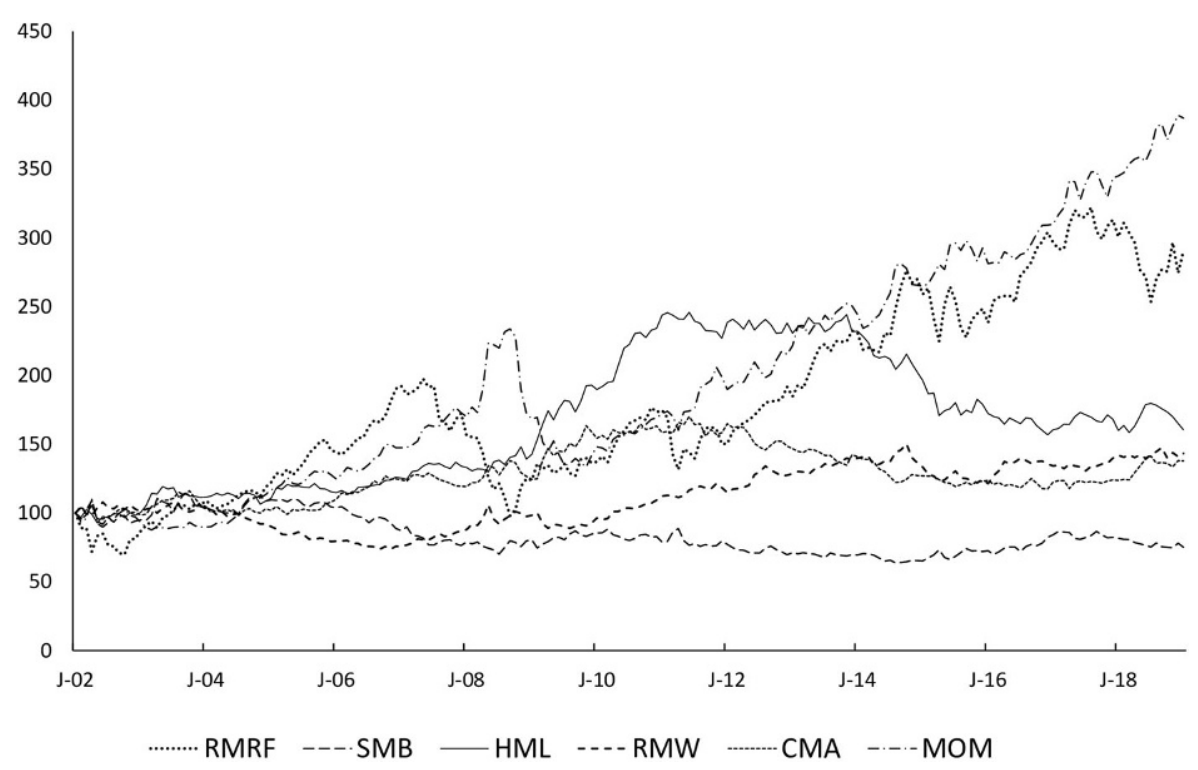

Fig. 1 Time series of the constructed factors. The figure shows the development of the market factor (RMRF), SMB, HML, RMW, CMA, and the momentum (MOM) factor over time

\subsection{Empirical results for the three- and six-factor model}

We estimate the three-factor and a six-factor model using four sets of 16 test assets, namely size-valuation (Size/BM), size-profitability (Size/OP), size-investment (Size/Inv), and size-momentum (Size/Mom) double-sorted portfolios.

Table 5 gives an overview of the results for the three-factor model regressions given by

$$
R_{i t}=a_{i}+b_{i} R M R F_{t}+s_{i} S M B_{t}+h_{i} H M L_{t}+\epsilon_{i t}
$$

using the Size/BM-sorted portfolios on the left hand side $^{2}$. Considering the coefficients on the market factor, $b_{i}$, which range from 0.80 to 1.09 , no clear increasing or decreasing patterns concerning the size or B/M sorted portfolios are observable. The coefficients for $s_{i}$ tend to decrease with increasing size, showing statistical significance with only few exceptions. The coefficients for $h_{i}$ are positive and significant with mostly strong test statistics for the highest B/M group. Considering the intercepts $\alpha$, we observe statistically significant estimates at the $5 \%$ significance level for four portfolios. The adjusted $R^{2}$ detects the best fit for the biggest size quartile, over all portfolios ranging between 0.35 and 0.89 . Our results partly confirm the findings by Ziegler et al. (2007), whose analysis covers the period from 1968 until 1995 , for the more recent data of our sample period. We also confirm the increasing

\footnotetext{
2 Results on the three-factor model using Size/OP, Size/Inv, and Size/Mom-sorted test assets yield similar results and are available upon request.
} 
Table 5 Results for the Fama-French three-factor model. The table presents regression estimates (left panel) and corresponding t-statistics (right panel) that are based on equation (5)

\begin{tabular}{|c|c|c|c|c|c|c|c|c|c|}
\hline \multicolumn{4}{|c|}{ Estimates for $\alpha$} & \multicolumn{6}{|c|}{$\mathrm{t}(\alpha)$} \\
\hline Size/BM & Low & 2 & 3 & High & Size/BM & Low & 2 & 3 & High \\
\hline Small & -0.26 & 0.21 & 0.03 & -0.02 & Small & -0.64 & 0.60 & 0.11 & -0.07 \\
\hline 2 & 0.26 & 0.03 & 0.41 & -0.08 & 2 & 1.44 & 0.19 & 2.54 & -0.43 \\
\hline 3 & 0.41 & 0.50 & 0.29 & 0.36 & 3 & 2.21 & 2.52 & 1.63 & 1.50 \\
\hline \multirow[t]{2}{*}{ Big } & 0.25 & -0.09 & 0.19 & -0.07 & big & 1.99 & -0.70 & 1.14 & -0.28 \\
\hline & \multicolumn{5}{|c|}{ Estimates for $b$} & \multicolumn{4}{|l|}{$t(b)$} \\
\hline Small & 0.96 & 1.03 & 0.80 & 1.04 & Small & 10.01 & 12.62 & 15.15 & 19.19 \\
\hline 2 & 1.00 & 0.94 & 0.93 & 1.01 & 2 & 23.21 & 23.26 & 24.2 & 22.58 \\
\hline 3 & 0.93 & 1.01 & 1.03 & 1.09 & 3 & 21.36 & 21.60 & 24.45 & 19.11 \\
\hline \multirow[t]{2}{*}{ Big } & 0.98 & 1.05 & 1.00 & 0.96 & Big & 34.01 & 33.82 & 25.57 & 16.31 \\
\hline & \multicolumn{5}{|c|}{ Estimates for $\mathrm{s}$} & \multicolumn{4}{|l|}{$\mathrm{t}(\mathrm{s})$} \\
\hline Small & 1.19 & 1.16 & 0.84 & 1.51 & Small & 8.25 & 9.46 & 10.64 & 14.14 \\
\hline 2 & 1.02 & 0.96 & 1.03 & 1.00 & 2 & 15.86 & 15.82 & 17.95 & 14.90 \\
\hline 3 & 0.54 & 0.58 & 0.62 & 0.81 & 3 & 8.28 & 8.31 & 9.71 & 9.45 \\
\hline \multirow[t]{2}{*}{ Big } & 0.00 & 0.11 & -0.19 & 0.04 & Big & 0.10 & 2.42 & -3.30 & 0.41 \\
\hline & \multicolumn{5}{|c|}{ Estimates for $\mathrm{h}$} & \multicolumn{4}{|l|}{$\mathrm{t}(\mathrm{h})$} \\
\hline Small & 0.08 & 0.20 & 0.27 & 0.50 & Small & 0.59 & 1.67 & 3.42 & 6.12 \\
\hline 2 & -0.33 & 0.04 & 0.16 & 0.37 & 2 & -5.16 & 0.64 & 2.76 & 5.57 \\
\hline 3 & -0.08 & 0.03 & 0.06 & 0.16 & 3 & -1.28 & 0.44 & 1.00 & 1.84 \\
\hline \multirow[t]{2}{*}{ Big } & -0.36 & 0.08 & 0.09 & 0.96 & Big & -8.32 & 1.65 & 1.48 & 10.85 \\
\hline & \multicolumn{9}{|c|}{ Adjusted $\mathrm{R}^{2}$} \\
\hline Small & 0.35 & 0.46 & 0.56 & 0.69 & & & & & \\
\hline 2 & 0.74 & 0.73 & 0.76 & 0.74 & & & & & \\
\hline 3 & 0.70 & 0.71 & 0.76 & 0.65 & & & & & \\
\hline Big & 0.89 & 0.89 & 0.85 & 0.74 & & & & & \\
\hline
\end{tabular}

importance of the HML factor with rising $\mathrm{B} / \mathrm{M}$ value, as reported by Ziegler et al. (2007).

Subsequently, we augment the three-factor model by the investment, profitability, and momentum factors, as given in equation (4). The results of the 16 Size-B/M portfolios are presented in Table 6. Adding these three factors does not lead to a drastic change in results in terms of the coefficients and test statistics for the 16 Size/BM portfolios. The coefficients of the market factor, SMB and HLM change only marginally for the six-factor model compared with the three-factor model.

The added profitability factor leads to the surprising result that most coefficients are negative. We do not find any relationship between the profitability factor loading and increasing or decreasing size or valuation. The results are similar for the investment factor. The highest B/M quartile shows three positive coefficients, of which two are statistically significant. The results on momentum reveal no clear pattern exhibiting insignificant or negative coefficients. For the six-factor model, we document significant intercept estimates for six portfolios, indicating no improvement over the three-factor model. 
Table 6 Results for the Fama-French six-factor model for size-valuation double-sorted portfolios. The table presents regression estimates (left panel) and corresponding t-statistics (right panel) that are based on equation (4)

\begin{tabular}{|c|c|c|c|c|c|c|c|c|c|}
\hline \multicolumn{4}{|c|}{ Estimates for $\alpha$} & \multirow[b]{2}{*}{ High } & \multicolumn{3}{|c|}{$\mathrm{t}(\alpha)$} & \multirow[b]{2}{*}{3} & \multirow[b]{2}{*}{ High } \\
\hline Size/BM & Low & 2 & 3 & & Size/BM & Low & 2 & & \\
\hline Small & -0.29 & 0.28 & 0.21 & 0.08 & Small & -0.69 & 0.80 & 0.93 & 0.35 \\
\hline 2 & 0.29 & -0.02 & 0.43 & 0.06 & 2 & 1.54 & -0.11 & 2.58 & 0.31 \\
\hline 3 & 0.48 & 0.56 & 0.41 & 0.51 & 3 & 2.57 & 2.83 & 2.24 & 2.22 \\
\hline \multirow[t]{2}{*}{ Big } & 0.29 & 0.05 & 0.05 & -0.14 & Big & 2.31 & 0.41 & 0.33 & -0.54 \\
\hline & \multicolumn{4}{|c|}{ Estimates for $\beta$} & & \multicolumn{3}{|l|}{$\mathrm{t}(\beta)$} & \\
\hline Small & 0.95 & 1.02 & 0.78 & 1.05 & Small & 9.57 & 12.38 & 14.82 & 12.98 \\
\hline 2 & 1.00 & 0.94 & 0.92 & 1.02 & 2 & 22.62 & 22.52 & 23.26 & 23.61 \\
\hline 3 & 0.91 & 1.01 & 1.02 & 1.11 & 3 & 20.75 & 21.56 & 23.58 & 20.53 \\
\hline \multirow[t]{2}{*}{ Big } & 0.97 & 1.04 & 1.03 & 0.97 & Big & 33.40 & 36.73 & 27.44 & 15.86 \\
\hline & \multicolumn{4}{|c|}{ Estimates for $\mathrm{s}$} & & \multicolumn{3}{|l|}{$\mathrm{t}(\mathrm{s})$} & \\
\hline Small & 1.20 & 1.08 & 0.77 & 1.07 & Small & 7.99 & 8.68 & 9.74 & 12.98 \\
\hline 2 & 0.99 & 0.97 & 1.03 & 0.90 & 2 & 14.77 & 15.47 & 17.30 & 13.85 \\
\hline 3 & 0.52 & 0.53 & 0.59 & 0.67 & 3 & 7.88 & 7.46 & 8.99 & 8.26 \\
\hline \multirow[t]{2}{*}{ Big } & -0.01 & 0.03 & -0.15 & 0.04 & Big & -0.14 & 0.82 & -2.58 & 0.48 \\
\hline & \multicolumn{4}{|c|}{ Estimates for $\mathrm{h}$} & & \multicolumn{3}{|l|}{$\mathrm{t}(\mathrm{h})$} & \\
\hline Small & 0.14 & 0.20 & 0.21 & 0.41 & Small & 0.86 & 1.50 & 2.52 & 4.76 \\
\hline 2 & -0.37 & 0.08 & 0.19 & 0.26 & 2 & -5.19 & 1.15 & 3.01 & 3.74 \\
\hline 3 & -0.05 & 0.02 & 0.02 & 0.03 & 3 & -0.67 & 0.24 & 0.36 & 0.38 \\
\hline \multirow[t]{2}{*}{ Big } & -0.33 & 0.01 & 0.08 & 0.99 & Big & -7.11 & 0.24 & 1.30 & 10.17 \\
\hline & \multicolumn{4}{|c|}{ Estimates for $r$} & & \multicolumn{2}{|l|}{$t(r)$} & & \\
\hline Small & -0.05 & -0.45 & -0.28 & -0.31 & Small & -0.28 & -3.18 & -3.10 & -3.30 \\
\hline 2 & -0.12 & 0.00 & -0.09 & -0.31 & 2 & -1.55 & 0.02 & -1.32 & -4.42 \\
\hline 3 & -0.23 & -0.34 & -0.08 & -0.54 & 3 & -3.07 & -4.23 & -1.14 & -5.84 \\
\hline \multirow[t]{2}{*}{ Big } & -0.16 & -0.31 & 0.34 & -0.04 & Big & -3.11 & -6.47 & 5.25 & -0.36 \\
\hline & \multicolumn{4}{|c|}{ Estimates for $\mathrm{c}$} & & \multicolumn{2}{|l|}{$\mathrm{t}(\mathrm{c})$} & & \\
\hline Small & -0.13 & -0.09 & 0.01 & 0.13 & Low & -0.74 & -0.61 & 0.11 & 1.37 \\
\hline 2 & 0.06 & -0.07 & -0.11 & 0.19 & 2 & 0.82 & -0.96 & -1.58 & 2.55 \\
\hline 3 & -0.17 & -0.04 & 0.21 & 0.18 & 3 & -2.29 & -0.53 & 0.29 & 1.94 \\
\hline \multirow[t]{2}{*}{ Big } & -0.13 & 0.05 & 0.15 & -0.05 & High & -2.58 & 1.03 & 2.41 & -0.46 \\
\hline & \multicolumn{3}{|c|}{ Estimates for $\mathrm{m}$} & & & \multicolumn{2}{|l|}{$\mathrm{t}(\mathrm{m})$} & & \\
\hline Small & 0.07 & 0.07 & -0.12 & -0.03 & Low & 0.58 & 0.71 & -1.93 & -0.53 \\
\hline 2 & 0.00 & 0.07 & 0.02 & -0.09 & 2 & -0.05 & 1.39 & 0.47 & -1.74 \\
\hline 3 & 0.02 & 0.04 & -0.11 & -0.02 & 3 & 0.36 & 0.79 & -2.13 & -0.34 \\
\hline \multirow[t]{2}{*}{ Big } & 0.02 & -0.07 & 0.03 & 0.10 & High & 0.66 & -2.08 & 0.65 & 1.35 \\
\hline & Adjust & $\mathrm{R}^{2}$ & & & & & & & \\
\hline Small & 0.35 & 0.48 & 0.59 & 0.70 & & & & & \\
\hline 2 & 0.74 & 0.73 & 0.76 & 0.77 & & & & & \\
\hline 3 & 0.71 & 0.73 & 0.76 & 0.71 & & & & & \\
\hline Big & 0.89 & 0.91 & 0.87 & 0.74 & & & & & \\
\hline
\end{tabular}


The results of the six-factor model on the Size/OP, Size/Inv, and Size/Mom portfolios are given in Tables 7, 8, and 9, respectively.

The results are similar to those for the Size/BM portfolios, with mostly negative coefficients on the profitability factor. The coefficients on the investment factors reveal positive and mostly significant estimates on the two lower quartiles for the Size/Inv-sorted portfolios, which turn negative and significant for the two higher quartiles, irrespective of size. The coefficients on the momentum factor for the Size/Mom-sorted portfolios show up positive and significant only for the two highest quartiles. Those on profitability remain negative for most portfolios throughout any sorts and quartiles. For most sorts, we observe positive intercepts, while the Size/Mom-sorted portfolios show the largest number of significant pricing errors with 10 significant estimates at a $5 \%$ significance level.

To test the three- and six-factor models estimated above, we conduct Gibbons, Ross, Shanken (GRS) tests according to Gibbons et al. (1989). We test the joint significance of the intercepts $\left(a_{i}\right)$ in equation (4) for the four double sorts (Size/BM, Size/OP, Size/Inv, and Size/Mom). Table 10 gives the test statistics, corresponding p-values, the average absolute intercepts, and the average $R^{2}$. We find joint significance of the pricing errors at the 5\% significance level for the Size/Inv and Size/Mom-sorted portfolios based on the three- and six-factor model, while both models capture the cross-sectional return variation, when considering Size/BMsorted portfolios and, to a lesser extent, when considering Size/OP-sorted portfolios. As noted by Fama and French (2015), Fama and French (2017), and Huynh (2018), solely relying on the GRS statistic does not allow for a conclusion to be made on superior model performance. Additionally, considering the average absolute intercepts $(A|\alpha|)$, we observe a higher GRS statistic and higher average absolute intercepts for the six-factor model through all sorts. Regarding the average adjusted $R^{2}$, the sixfactor model exhibits higher values compared with the three-factor model. Overall, the metrics presented in Table 10 do not deliver convincing evidence of superior performance of the six-factor model compared with the three-factor model.

Following Fama and French (2015), Fama and French (2017), and relying on Huberman and Kandel (1987), we examine any potential redundant factors using factor-spanning tests, that is, we regress returns to one factor on a constant and the remaining five factor returns. The results are presented in Table 11. We find statistically insignificant intercepts for all but the market and momentum factor at the 5\% significance level. Although the intercepts for SMB, HML and RMW are at least more than one standard deviation away from zero, the intercept for CMA is clearly insignificant. Consequently, removing the CMA factor would not negatively impact the mean-variance-efficient tangency portfolio that is implied by the remaining five factors. This result corresponds partly to the findings of Fama and French (2017), who detect redundant CMA and SMB factors for the European portfolios, while their results indicate significant intercepts for the SMB and HML factors. To examine whether the results of the previous sections are influenced by the specific factor construction according to Fama and French (2015), we calculate profitability and investment growth using two alternative approaches, namely gross profitability, as proposed by Novy-Marx (2013) and Ball et al. (2015), and investment 
Table 7 Results for the Fama-French six-factor model for size-operating profitability double-sorted portfolios. The table presents regression estimates (left panel) and corresponding t-statistics (right panel) that are based on equation (4)

\begin{tabular}{|c|c|c|c|c|c|c|c|c|c|}
\hline \multicolumn{4}{|c|}{ Estimates for $\alpha$} & \multicolumn{5}{|c|}{$\mathrm{t}(\alpha)$} & \multirow[b]{2}{*}{ High } \\
\hline Size/OP & Low & 2 & 3 & High & Size/OP & Low & 2 & 3 & \\
\hline Small & 0.00 & 0.47 & 0.60 & -0.53 & Small & 0.00 & 1.72 & 1.99 & -1.51 \\
\hline 2 & 0.11 & 0.53 & 0.10 & 0.45 & 2 & 0.57 & 3.13 & 0.44 & 1.75 \\
\hline 3 & 0.66 & 0.38 & 0.78 & 0.53 & 3 & 3.22 & 1.75 & 3.08 & 2.00 \\
\hline \multirow[t]{2}{*}{ Big } & 0.53 & 0.35 & 0.46 & 0.04 & Big & 2.34 & 1.85 & 2.44 & 0.31 \\
\hline & \multicolumn{4}{|c|}{ Estimates for $b$} & & \multicolumn{3}{|l|}{$\mathrm{t}(\mathrm{b})$} & \\
\hline Small & 0.88 & 0.84 & 0.99 & 0.86 & Small & 13.17 & 13.17 & 14.09 & 10.35 \\
\hline 2 & 0.90 & 0.83 & 1.03 & 0.81 & 2 & 19.54 & 20.72 & 19.11 & 13.40 \\
\hline 3 & 0.86 & 0.94 & 0.87 & 1.05 & 3 & 17.84 & 18.41 & 14.73 & 16.75 \\
\hline \multirow[t]{2}{*}{ Big } & 0.88 & 0.86 & 1.01 & 0.93 & Big & 16.44 & 19.12 & 22.58 & 29.19 \\
\hline & \multicolumn{4}{|c|}{ Estimates for s } & & \multicolumn{3}{|l|}{$\mathrm{t}(\mathrm{s})$} & \\
\hline Small & 0.96 & 0.75 & 0.98 & 0.91 & Small & 9.59 & 7.82 & 9.23 & 7.31 \\
\hline 2 & 0.93 & 0.75 & 0.98 & 0.82 & 2 & 13.28 & 12.33 & 11.93 & 8.89 \\
\hline 3 & 0.47 & 0.49 & 0.49 & 0.51 & 3 & 6.40 & 6.33 & 5.50 & 5.41 \\
\hline \multirow[t]{2}{*}{ Big } & -0.18 & -0.05 & 0.07 & -0.16 & Big & -2.23 & -0.68 & 0.98 & -3.23 \\
\hline & \multicolumn{4}{|c|}{ Estimates for $\mathrm{h}$} & & \multicolumn{3}{|l|}{$\mathrm{t}(\mathrm{h})$} & \\
\hline Small & 0.39 & 0.25 & 0.26 & -0.02 & Small & 3.66 & 2.48 & 2.33 & -0.13 \\
\hline 2 & 0.01 & 0.07 & 0.13 & 0.08 & 2 & -0.54 & 1.04 & 1.49 & 0.81 \\
\hline 3 & -0.03 & -0.01 & 0.11 & -0.08 & 3 & -0.39 & -0.17 & 1.19 & -0.79 \\
\hline \multirow[t]{2}{*}{ Big } & 0.16 & -0.03 & -0.23 & 0.10 & Big & 1.88 & -0.43 & -3.22 & 1.90 \\
\hline & \multicolumn{4}{|c|}{ Estimates for $\mathrm{r}$} & & \multicolumn{3}{|l|}{$t(r)$} & \\
\hline Small & -0.38 & -0.31 & -0.25 & -0.13 & Small & -3.28 & -2.82 & -2.07 & -0.88 \\
\hline 2 & -0.43 & -0.19 & -0.17 & 0.30 & 2 & -5.40 & -2.69 & -1.85 & 2.90 \\
\hline 3 & -0.38 & -0.25 & -0.23 & -0.17 & 3 & -4.54 & -2.88 & -2.22 & -1.58 \\
\hline \multirow[t]{2}{*}{ Big } & -1.36 & -0.32 & -0.17 & 0.30 & Big & -13.37 & -4.16 & -2.21 & 5.41 \\
\hline & \multicolumn{4}{|c|}{ Estimates for c } & & \multicolumn{2}{|l|}{$\mathrm{t}(\mathrm{c})$} & & \\
\hline Small & 0.14 & 0.10 & -0.02 & 0.31 & Small & 1.23 & 0.92 & -0.13 & 2.16 \\
\hline 2 & 0.10 & 0.08 & 0.00 & 0.21 & 2 & 1.24 & 1.24 & 0.03 & 1.97 \\
\hline 3 & 0.10 & 0.12 & -0.03 & 0.024 & 3 & 1.26 & 1.35 & -0.25 & 0.37 \\
\hline \multirow[t]{2}{*}{ Big } & 0.09 & 0.17 & 0.26 & -0.03 & Big & 0.93 & 2.15 & 3.39 & -0.60 \\
\hline & \multicolumn{4}{|c|}{ Estimates for $\mathrm{m}$} & & \multicolumn{2}{|l|}{$\mathrm{t}(\mathrm{m})$} & & \\
\hline Small & -0.04 & -0.12 & 0.03 & -0.14 & Small & -0.46 & -1.55 & 0.31 & -1.44 \\
\hline 2 & 0.07 & -0.06 & -0.06 & -0.14 & 2 & 1.23 & -1.28 & -0.93 & -1.93 \\
\hline 3 & 0.01 & -0.06 & 0.00 & -0.09 & 3 & 0.12 & -1.04 & -0.03 & -1.17 \\
\hline \multirow[t]{2}{*}{ Big } & -0.07 & -0.13 & -0.03 & 0.05 & Big & -1.09 & -2.52 & -0.57 & 1.33 \\
\hline & \multicolumn{4}{|c|}{ Adjusted $\mathrm{R}^{2}$} & & & & & \\
\hline Low & 0.55 & 0.53 & 0.54 & 0.38 & & & & & \\
\hline 2 & 0.69 & 0.71 & 0.67 & 0.51 & & & & & \\
\hline 3 & 0.64 & 0.66 & 0.56 & 0.62 & & & & & \\
\hline High & 0.76 & 0.74 & 0.77 & 0.89 & & & & & \\
\hline
\end{tabular}


Table 8 Results for the Fama-French six-factor model for size-investment double-sorted portfolios. The table presents regression estimates (left panel) and corresponding t-statistics (right panel) that are based on equation (4)

\begin{tabular}{|c|c|c|c|c|c|c|c|c|c|}
\hline \multicolumn{4}{|c|}{ Estimates for $\alpha$} & \multirow[b]{2}{*}{ High } & \multirow[b]{2}{*}{ Size/Inv } & \multicolumn{3}{|l|}{$\mathrm{t}(\alpha)$} & \multirow[b]{2}{*}{ High } \\
\hline Size/Inv & Low & 2 & 3 & & & Low & 2 & 3 & \\
\hline Small & 0.06 & 0.04 & 1.13 & -0.56 & Small & 0.24 & 0.16 & 3.03 & -1.67 \\
\hline 2 & -0.01 & 0.46 & 0.63 & -0.18 & 2 & -0.06 & 2.64 & 3.71 & -0.99 \\
\hline 3 & 0.36 & 0.54 & 0.64 & 0.55 & 3 & 1.37 & 3.14 & 3.46 & 2.97 \\
\hline \multirow[t]{2}{*}{ Big } & -0.01 & 0.13 & 0.24 & 0.19 & Big & -0.04 & 0.91 & 1.47 & 1.21 \\
\hline & \multicolumn{4}{|c|}{ Estimates for $\beta$} & & \multicolumn{3}{|l|}{$\mathrm{t}(\beta)$} & \\
\hline Small & 1.03 & 0.92 & 0.76 & 0.99 & Small & 17.82 & 14.08 & 8.73 & 12.66 \\
\hline 2 & 1.11 & 0.78 & 0.96 & 1.05 & 2 & 23.98 & 19.13 & 24.19 & 25.07 \\
\hline 3 & 0.99 & 0.96 & 0.90 & 1.13 & 3 & 16.08 & 23.72 & 20.74 & 25.92 \\
\hline \multirow[t]{2}{*}{ Big } & 0.97 & 1.10 & 1.02 & 0.98 & Big & 19.91 & 32.22 & 27.09 & 26.66 \\
\hline & \multicolumn{4}{|c|}{ Estimates for $\mathrm{s}$} & & \multicolumn{3}{|l|}{$\mathrm{t}(\mathrm{s})$} & \\
\hline Small & 1.14 & 0.81 & 0.90 & 0.92 & Small & 13.07 & 8.23 & 6.78 & 7.75 \\
\hline 2 & 1.13 & 0.78 & 0.85 & 1.19 & 2 & 16.07 & 12.62 & 14.20 & 18.74 \\
\hline 3 & 0.62 & 0.55 & 0.48 & 0.67 & 3 & 6.64 & 8.94 & 7.24 & 10.22 \\
\hline \multirow[t]{2}{*}{ Big } & 0.11 & 0.03 & -0.14 & 0.05 & Big & 1.44 & 0.52 & -2.53 & 0.84 \\
\hline & \multicolumn{4}{|c|}{ Estimates for $h$} & & \multicolumn{3}{|l|}{$\mathrm{t}(\mathrm{h})$} & \\
\hline Small & 0.37 & 0.25 & 0.25 & 0.06 & Small & 4.03 & 2.40 & 1.83 & 0.47 \\
\hline 2 & -0.01 & 0.21 & 0.00 & 0.12 & 2 & -0.20 & 3.18 & 0.05 & 1.77 \\
\hline 3 & 0.05 & 0.02 & -0.06 & 0.03 & 3 & 0.50 & 0.33 & -0.82 & 0.40 \\
\hline \multirow[t]{2}{*}{ Big } & 0.05 & 0.11 & 0.01 & -0.07 & Big & 0.69 & 2.08 & 0.22 & -1.26 \\
\hline & \multicolumn{4}{|c|}{ Estimates for $r$} & & \multicolumn{3}{|l|}{$t(r)$} & \\
\hline Small & -0.23 & -0.31 & -0.35 & -0.38 & Small & -2.32 & -2.76 & -2.34 & -2.79 \\
\hline 2 & -0.08 & -0.11 & -0.20 & -0.13 & 2 & -0.95 & -1.59 & -2.93 & -1.81 \\
\hline 3 & -0.26 & -0.27 & -0.30 & -0.28 & 3 & -2.48 & -3.82 & -4.01 & -3.74 \\
\hline \multirow[t]{2}{*}{ Big } & -0.35 & -0.16 & 0.22 & -0.07 & Big & -4.21 & -2.71 & 3.38 & -1.17 \\
\hline & \multicolumn{4}{|c|}{ Estimates for $\mathrm{c}$} & & \multicolumn{2}{|l|}{$\mathrm{t}(\mathrm{c})$} & & \\
\hline Small & 0.20 & 0.12 & -0.31 & -0.30 & Small & 1.98 & 1.08 & -2.08 & -2.24 \\
\hline 2 & 0.56 & 0.07 & -0.13 & -0.40 & 2 & 7.05 & 0.93 & -1.87 & -5.61 \\
\hline 3 & 0.16 & 0.00 & -0.18 & -0.11 & 3 & 1.54 & 0.06 & -2.42 & -1.43 \\
\hline \multirow[t]{2}{*}{ Big } & 0.50 & 0.09 & 0.03 & -0.45 & Big & 5.94 & 1.59 & 0.39 & -7.16 \\
\hline & \multicolumn{3}{|c|}{ Estimates for $\mathrm{m}$} & & & $\mathrm{t}(\mathrm{m})$ & & & \\
\hline Small & -0.06 & 0.01 & 0.01 & -0.05 & Small & -0.93 & 0.10 & 0.15 & -0.58 \\
\hline 2 & -0.04 & -0.03 & 0.01 & 0.03 & 2 & -0.82 & -0.54 & 0.16 & 0.61 \\
\hline 3 & 0.13 & -0.07 & -0.06 & 0.04 & 3 & 1.85 & -1.44 & -1.19 & 0.79 \\
\hline \multirow[t]{2}{*}{ Big } & 0.11 & -0.07 & -0.08 & -0.13 & Big & 1.85 & -1.70 & -1.88 & -3.00 \\
\hline & \multicolumn{4}{|c|}{ Adjusted $\mathrm{R}^{2}$} & & & & & \\
\hline Small & 0.67 & 0.54 & 0.34 & 0.50 & & & & & \\
\hline 2 & 0.76 & 0.68 & 0.77 & 0.80 & & & & & \\
\hline 3 & 0.57 & 0.77 & 0.73 & 0.79 & & & & & \\
\hline Big & 0.72 & 0.89 & 0.87 & 0.87 & & & & & \\
\hline
\end{tabular}


Table 9 Results for the Fama-French six-factor model for size-momentum double-sorted portfolios. The table presents regression estimates (left panel) and corresponding t-statistics (right panel) that are based on equation (4)

\begin{tabular}{|c|c|c|c|c|c|c|c|c|c|}
\hline \multicolumn{4}{|c|}{ Estimates for $\alpha$} & \multicolumn{6}{|c|}{$\mathrm{t}(\alpha)$} \\
\hline Size/Mom & Low & 2 & 3 & High & Size/Mom & Low & 2 & 3 & High \\
\hline Small & -0.66 & 0.27 & 0.61 & 0.80 & Small & -2.64 & 1.16 & 2.16 & 2.70 \\
\hline 2 & -0.60 & 0.10 & 0.71 & 0.66 & 2 & -3.17 & 0.57 & 3.70 & 4.33 \\
\hline 3 & 0.12 & 0.60 & 0.27 & 0.83 & 3 & 0.44 & 3.68 & 1.31 & 4.50 \\
\hline \multirow[t]{2}{*}{ Big } & 1.25 & 0.47 & -0.02 & -0.06 & Big & 4.73 & 2.94 & -0.14 & -0.35 \\
\hline & \multicolumn{5}{|c|}{ Estimates for $\beta$} & \multicolumn{4}{|l|}{$\mathrm{t}(\beta)$} \\
\hline Small & 1.06 & 0.81 & 0.99 & 0.84 & Small & 17.90 & 14.72 & 14.83 & 12.11 \\
\hline 2 & 1.08 & 0.85 & 0.92 & 1.02 & 2 & 24.21 & 20.28 & 20.48 & 28.50 \\
\hline 3 & 1.12 & 0.93 & 0.91 & 1.05 & 3 & 17.91 & 24.26 & 18.54 & 24.19 \\
\hline \multirow[t]{2}{*}{ Big } & 1.00 & 1.01 & 1.01 & 1.12 & Big & 16.16 & 26.93 & 34.39 & 26.88 \\
\hline & \multicolumn{5}{|c|}{ Estimates for s } & \multicolumn{4}{|l|}{$\mathrm{t}(\mathrm{s})$} \\
\hline Small & 0.98 & 1.06 & 0.99 & 0.93 & Small & 11.00 & 12.73 & 9.87 & 8.86 \\
\hline 2 & 1.10 & 0.86 & 0.94 & 0.98 & 2 & 16.41 & 13.60 & 13.80 & 18.04 \\
\hline 3 & 0.67 & 0.63 & 0.55 & 0.55 & 3 & 7.07 & 10.86 & 7.44 & 8.43 \\
\hline \multirow[t]{2}{*}{ Big } & 0.13 & -0.19 & 0.05 & 0.10 & Big & 1.41 & -3.44 & 1.03 & 1.59 \\
\hline & \multicolumn{5}{|c|}{ Estimates for $\mathrm{h}$} & \multicolumn{4}{|l|}{$\mathrm{t}(\mathrm{h})$} \\
\hline Small & 0.54 & 0.09 & -0.02 & 0.31 & Small & 5.72 & 1.06 & -0.17 & 2.84 \\
\hline 2 & -0.08 & 0.10 & 0.24 & -0.03 & 2 & -1.12 & 1.53 & 3.41 & -0.45 \\
\hline 3 & -0.01 & 0.02 & 0.12 & -0.11 & 3 & -0.09 & 0.36 & 1.58 & -1.53 \\
\hline \multirow[t]{2}{*}{ Big } & -0.07 & -0.05 & 0.23 & -0.21 & Big & -0.72 & -0.84 & 4.98 & -3.22 \\
\hline & \multicolumn{5}{|c|}{ Estimates for $\mathrm{r}$} & \multicolumn{4}{|l|}{$\mathrm{t}(\mathrm{r})$} \\
\hline Small & -0.40 & -0.29 & -0.15 & -0.15 & Small & -3.89 & -3.09 & -1.34 & -1.22 \\
\hline 2 & -0.23 & -0.14 & -0.14 & -0.06 & 2 & -3.03 & -1.97 & -1.79 & -0.92 \\
\hline 3 & -0.29 & -0.27 & -0.22 & -0.26 & 3 & -2.72 & -4.11 & -2.61 & -3.52 \\
\hline \multirow[t]{2}{*}{ Big } & 0.20 & -0.29 & -0.01 & -0.04 & Big & 1.83 & -4.45 & -0.22 & -0.53 \\
\hline & \multicolumn{5}{|c|}{ Estimates for c } & \multicolumn{4}{|l|}{$\mathrm{t}(\mathrm{c})$} \\
\hline Small & 0.00 & 0.10 & 0.16 & -0.07 & Small & -0.05 & 1.02 & 1.41 & -0.55 \\
\hline 2 & 0.09 & -0.02 & 0.01 & -0.02 & 2 & 1.17 & -0.25 & 0.10 & -0.27 \\
\hline 3 & 0.11 & -0.13 & -0.05 & -0.11 & 3 & 1.00 & -1.98 & -0.60 & -1.55 \\
\hline \multirow[t]{2}{*}{ Big } & -0.14 & -0.07 & 0.04 & -0.08 & Big & -1.34 & -1.12 & 0.85 & -1.11 \\
\hline & \multicolumn{5}{|c|}{ Estimates for $\mathrm{m}$} & \multicolumn{4}{|l|}{$\mathrm{t}(\mathrm{m})$} \\
\hline Low & -0.18 & 0.02 & -0.03 & 0.17 & Low & -2.61 & 0.35 & -0.33 & 2.12 \\
\hline 2 & -0.31 & -0.03 & 0.12 & 0.18 & 2 & -6.02 & -0.64 & 2.37 & 4.24 \\
\hline 3 & -0.24 & -0.15 & 0.11 & 0.15 & 3 & -3.33 & -3.36 & 2.01 & 3.07 \\
\hline \multirow[t]{2}{*}{ High } & -1.06 & -0.46 & 0.09 & 0.61 & High & -14.68 & -10.53 & 2.63 & 12.55 \\
\hline & \multicolumn{4}{|c|}{ Adjusted $\mathrm{R}^{2}$} & & & & & \\
\hline Small & 0.70 & 0.59 & 0.54 & 0.46 & & & & & \\
\hline 2 & 0.79 & 0.70 & 0.70 & 0.81 & & & & & \\
\hline 3 & 0.66 & 0.70 & 0.66 & 0.76 & & & & & \\
\hline Big & 0.79 & 0.89 & 0.90 & 0.84 & & & & & \\
\hline
\end{tabular}


Table 10 Test statistics of the three and six-factor models. The table shows the GRS test statistic, corresponding p-values, the average intercepts, $(A|\alpha|)$, and the average $R^{2}\left(A R^{2}\right)$

\begin{tabular}{llllll}
\hline \multirow{2}{*}{ Size/BM } & & GRS & $\mathbf{p}(\mathbf{G R S})$ & $A|\alpha|$ & $A R^{2}$ \\
& 3-factor & 1.09 & 0.36 & 0.19 & 0.71 \\
Size/OP & 6-factor & 1.26 & 0.22 & 0.20 & 0.73 \\
& 3-factor & 1.54 & 0.09 & 0.28 & 0.61 \\
Size/Inv & 6-factor & 1.72 & 0.06 & 0.33 & 0.75 \\
& 3-factor & 2.08 & 0.01 & 0.31 & 0.69 \\
Size/Mom & 6-factor & 2.74 & 0.00 & 0.33 & 0.72 \\
& 3-factor & 7.01 & 0.00 & 0.48 & 0.68 \\
& 6-factor & 6.87 & 0.00 & 0.50 & 0.73 \\
\hline
\end{tabular}

Table 11 Factor-spanning tests. The table presents (row-wise) estimated coefficients, where $a$ denotes the intercept, t-statistics are given in parentheses, and the last column contains the adjusted $R^{2}$

\begin{tabular}{lllllllll}
\hline & a & RMRF & SMB & HML & RMW & CMA & MOM & $\mathbf{R}^{2}$ \\
RMRF & 0.68 & & -0.71 & 0.23 & 0.03 & -0.32 & -0.16 & 0.35 \\
& $(2.28)$ & & $(-7.42)$ & $(2.05)$ & $(0.21)$ & $(-2.65)$ & $(-2.0)$ & \\
SMB & 0.23 & -0.31 & & -0.20 & -0.22 & 0.18 & -0.03 & 0.36 \\
& $(1.16)$ & $(-7.42)$ & & $(-2.75)$ & $(-2.82)$ & $(2.24)$ & $(-0.52)$ & \\
HML & 0.31 & 0.09 & -0.18 & & -0.04 & 0.41 & -0.13 & 0.22 \\
& $(1.67)$ & $(2.05)$ & $(-2.75)$ & & $(-0.58)$ & $(5.80)$ & $(-2.64)$ & \\
RMW & 0.13 & 0.01 & -0.17 & -0.04 & & -0.10 & 0.18 & 0.14 \\
& $(0.72)$ & $(0.21)$ & $(-2.82)$ & $(-0.58)$ & & $(-1.39)$ & $(3.85)$ & \\
CMA & 0.05 & -0.11 & 0.14 & 0.35 & & -0.10 & 0.12 & 0.23 \\
& $(0.31)$ & $(-2.65)$ & $(2.24)$ & $(5.80)$ & $(-1.39)$ & & $(2.45)$ & \\
MOM & 0.76 & -0.12 & -0.05 & -0.25 & 0.39 & 0.25 & & 0.15 \\
& $(3.01)$ & $(-2.00)$ & $(-0.52)$ & $(-2.64)$ & $(3.85)$ & $(2.45)$ & & \\
\hline
\end{tabular}

growth, as used in Cooper et al. (2008). However, we arrive at qualitatively similar results (detailed results are available upon request).

\section{Conclusion}

We implemented the Fama-French three- and a six-factor model by including profitability, investment, and momentum for the German market. Looking at the factors alone, the newly introduced profitability and investment factors do not show attractive, statistically significant returns on a long/short basis for the German equity market. The results from Fama-MacBeth regressions also show no evidence for an investment or a profitability premium. Comparing the results of the three-factor model with the results of the six-factor model for the German equity market, the improvement in explainability is rather marginal. The average adjusted $R^{2}$ of the six-factor model increases only slightly compared with the three-factor model. We implement the six-factor model using portfolios double-sorted on size and value, investment, profitability, or momentum. We find that many of the regression inter- 
cepts for the RMW and CMA factors show strong statistical significance regardless of the left hand side sorting combination. Considering the GRS test statistics, we find evidence that the Fama-French six-factor model captures the cross-sectional return variation, when explaining size-valuation-sorted portfolio returns and, to a lesser extent, for size-operating profitability-sorted portfolios. Overall, the international evidence with respect to the significance of the newly introduced factors, operating profitability and investment, in explaining asset returns, is neither supported by our implementation of Fama-MacBeth regressions, nor by implementing a six-factor model for the German stock market.

Funding Open Access funding enabled and organized by Projekt DEAL.

Open Access This article is licensed under a Creative Commons Attribution 4.0 International License, which permits use, sharing, adaptation, distribution and reproduction in any medium or format, as long as you give appropriate credit to the original author(s) and the source, provide a link to the Creative Commons licence, and indicate if changes were made. The images or other third party material in this article are included in the article's Creative Commons licence, unless indicated otherwise in a credit line to the material. If material is not included in the article's Creative Commons licence and your intended use is not permitted by statutory regulation or exceeds the permitted use, you will need to obtain permission directly from the copyright holder. To view a copy of this licence, visit http://creativecommons.org/licenses/by/4. $0 \%$.

\section{Variable construction and corresponding Bloomberg codes}

\section{Fama French (2015) variables}

Market Capitalization :

Market Capitalization $\mathrm{CY}_{t-1} \rightarrow \$ R R 913_{\mathrm{CY}_{t-1}}$

Book-to-Market Equity :

$$
\frac{\text { Total Equity }_{\mathrm{FY}_{t-1}}}{\left(\frac{\text { Market Capitalization }_{\mathrm{CY}_{t-1}} \times \text { Shares Outstanding }_{\mathrm{CY}_{t-1}}}{\text { Shares Outstanding }_{\mathrm{FY}_{t-1}}}\right)} \rightarrow \frac{\$ R R 007_{\mathrm{FY}_{t-1}}}{\left(\frac{\$ R R 913_{\mathrm{CY}_{t-1}} \times \$ B S 081_{\mathrm{CY}_{t-1}}}{\$ B S 081_{\mathrm{FY}}}\right)}
$$

Operating Profitability $t$ :

$\underline{\text { Operating Income }} \mathrm{FY}_{t-1}-$ Operating Expenses ${ }_{\mathrm{FY}_{t-1}}-$ Interest Expenses FY $_{t-1}$

$$
\text { Total Equity } \mathrm{FY}_{t-1}
$$$$
\rightarrow \frac{\$ \mathrm{IS} 033_{\mathrm{FY}_{t-1}}-\$ I S 032_{\mathrm{FY}_{t-1}}-\$ \mathrm{IS} 034_{\mathrm{FY}_{t-1}}}{\$ \mathrm{RR} 010_{\mathrm{FY}_{t-1}}}
$$

Investment $_{t}$ :

$$
\frac{\text { Total Assets }}{\mathrm{FY}_{t-1}} \underset{\text { Total Assets } \mathrm{FY}_{t-2}}{\text { TBS035 }} \rightarrow \frac{\$ \mathrm{FY}_{t-1}}{\$ \mathrm{BS} 035_{\mathrm{FY}}}
$$




\section{Factor construction}

Independent sorts are used to assign stocks into two size groups and three groups according to B/M, OP, and Inv. Regarding size sorts, stocks are classified into small (S) and big (B). Considering valuation $(\mathrm{B} / \mathrm{M})$, stocks are classified as high $(\mathrm{H})$, neutral $(\mathrm{N})$ and low $(\mathrm{L})$. As for the operating profitability (OP), stocks are classified as robust $(\mathrm{R})$, neutral $(\mathrm{N})$ and weak $(\mathrm{W})$. Stocks are grouped into three investment groups (Inv), being conservative (C), neutral $(\mathrm{N})$ and aggressive (A), and momentum is based on past winners $(\mathrm{W})$, neutral performers $(\mathrm{N})$, and losers $(\mathrm{L})$.

The size factor (SMB) is calculated by three size factors $S M B_{B / M}, S M B_{O P}$, $S M B_{I n v}$, and $S M B_{M O M}$ given by

$$
\begin{aligned}
S M B_{B / M} & =\left(S_{H}+S_{N}+S_{L}\right) / 3-\left(B_{H}+B_{N}+B_{L}\right) / 3 \\
S M B_{O P} & =\left(S_{R}+S_{N}+S_{W}\right) / 3-\left(B_{R}+B_{N}+B_{W}\right) / 3 \\
S M B_{I n v} & =\left(S_{C}+S_{N}+S_{A}\right) / 3-\left(B_{C}+B_{N}+B_{A}\right) / 3 \\
S M B_{M O M} & =\left(S_{C}+S_{N}+S_{A}\right) / 3-\left(B_{W}+B_{N}+B_{L}\right) / 3
\end{aligned}
$$

The final factors SMB, HLM, RMW, CMA, and MOM are then derived as

$$
\begin{aligned}
S M B & =\left(S M B_{B / M}+S M B_{O P}+S M B_{I n v}\right) / 3 \\
H M L & =\left(S_{H}+B_{H}\right) / 2-\left(S_{L}+B_{L}\right) / 2 \\
R M W & =\left(S_{R}+B_{R}\right) / 2-\left(S_{W}+B_{W}\right) / 2 \\
C M A & =\left(S_{C}+B_{C}\right) / 2-\left(S_{A}+B_{A}\right) / 2 \\
M O M & =\left(S_{W}+B_{W}\right) / 2-\left(S_{L}+B_{L}\right) / 2
\end{aligned}
$$




\section{Additional Tables}

Table 12 Sample selection filters. The table presents the filters applied for sample selection, starting with the CDAX constituents, filtering those constituents that are available on Bloomberg, excluding financials and filtering those companies with a positive book-to-market ratio, and those companies for which profitability and investment measures according to Fama and French (2015) can be calculated. The last column presents the final number of sample companies for which monthly prices are available

\begin{tabular}{llllllll}
\hline & CDAX & Bloomberg & $\begin{array}{l}\text { ex. } \\
\text { financ. }\end{array}$ & $\begin{array}{l}\text { B/M } \\
\text { pos. }\end{array}$ & OP & INV & MOM \\
\hline 30.06 .2002 & 789 & 691 & 572 & 516 & 481 & 480 & 477 \\
30.06 .2003 & 737 & 683 & 575 & 470 & 429 & 429 & 417 \\
30.06 .2004 & 709 & 662 & 564 & 435 & 401 & 396 & 385 \\
30.06 .2005 & 681 & 638 & 543 & 419 & 379 & 377 & 362 \\
30.06 .2006 & 675 & 635 & 535 & 423 & 400 & 394 & 369 \\
30.06 .2007 & 690 & 648 & 536 & 436 & 418 & 413 & 403 \\
30.06 .2008 & 683 & 641 & 530 & 438 & 420 & 412 & 399 \\
30.06 .2009 & 652 & 611 & 514 & 415 & 385 & 383 & 382 \\
30.06 .2010 & 618 & 579 & 491 & 385 & 348 & 343 & 333 \\
30.06 .2011 & 583 & 560 & 475 & 378 & 347 & 345 & 329 \\
30.06 .2012 & 554 & 536 & 531 & 450 & 369 & 342 & 320 \\
30.06 .2013 & 511 & 491 & 419 & 343 & 318 & 317 & 309 \\
30.06 .2014 & 485 & 466 & 396 & 323 & 300 & 295 & 288 \\
30.06 .2015 & 447 & 430 & 369 & 299 & 277 & 277 & 270 \\
30.06 .2016 & 425 & 408 & 352 & 291 & 273 & 272 & 264 \\
30.06 .2017 & 417 & 403 & 343 & 290 & 270 & 268 & 264 \\
30.06 .2018 & 423 & 409 & 347 & 287 & 264 & 264 & 256 \\
\hline
\end{tabular}


Table 13 Average monthly excess returns and the t-statistic of the $3 \times 3$ triple-sorted portfolios for June 2002 until June 2019

\begin{tabular}{|c|c|c|c|c|c|c|c|}
\hline \multicolumn{8}{|l|}{ BM/OP } \\
\hline \multicolumn{4}{|c|}{ Average returns } & \multicolumn{4}{|l|}{ T-statistic } \\
\hline \multicolumn{8}{|l|}{ Small } \\
\hline & Low BM & 2 & High BM & & Low BM & 2 & High BM \\
\hline Low OP & 0.48 & 0.65 & 0.75 & Low OP & 1.34 & 1.86 & 2.01 \\
\hline 2 & 0.95 & 1.07 & 1.34 & 2 & 2.21 & 2.87 & 3.63 \\
\hline High OP & 1.33 & 0.70 & 1.37 & High OP & 3.36 & 1.95 & 3.41 \\
\hline \multicolumn{8}{|l|}{$\overline{\text { Big }}$} \\
\hline & Low BM & 2 & High BM & & Low BM & 2 & High BM \\
\hline Low OP & 0.70 & 0.78 & 1.31 & Low OP & 1.94 & 1.68 & 2.68 \\
\hline 2 & 0.95 & 0.89 & 1.02 & 2 & 1.02 & 2.40 & 2.04 \\
\hline High OP & 0.68 & 0.90 & 1.08 & High OP & 1.89 & 2.09 & 2.10 \\
\hline \multicolumn{8}{|l|}{ BM/INV } \\
\hline \multicolumn{4}{|c|}{ Average returns } & \multicolumn{4}{|l|}{ T-statistic } \\
\hline \multicolumn{8}{|l|}{ Small } \\
\hline & Low BM & 2 & High BM & & Low BM & 2 & High BM \\
\hline Low INV & 0.63 & 0.53 & 0.91 & Low INV & 1.07 & 1.36 & 2.48 \\
\hline 2 & 1.25 & 0.94 & 1.34 & 2 & 3.61 & 3.03 & 3.85 \\
\hline $\begin{array}{l}\text { High } \\
\text { INV }\end{array}$ & 0.60 & 0.79 & 0.96 & $\begin{array}{l}\text { High } \\
\text { INV }\end{array}$ & 1.52 & 2.00 & 2.37 \\
\hline \multicolumn{8}{|l|}{ Big } \\
\hline & Low BM & 2 & High BM & & Low BM & 2 & High BM \\
\hline Low INV & 0.83 & 1.02 & 1.26 & Low INV & 2.58 & 2.28 & 2.75 \\
\hline 2 & 1.05 & 0.783 & 0.90 & 2 & 2.76 & 1.87 & 1.70 \\
\hline $\begin{array}{l}\text { High } \\
\text { INV }\end{array}$ & 0.51 & 0.71 & 1.30 & $\begin{array}{l}\text { High } \\
\text { INV }\end{array}$ & 1.17 & 1.69 & 2.56 \\
\hline \multicolumn{8}{|l|}{ OP/INV } \\
\hline \multicolumn{4}{|c|}{ Average returns } & \multicolumn{4}{|l|}{ T-statistic } \\
\hline \multicolumn{8}{|l|}{ Small } \\
\hline & Low OP & 2 & High OP & & Low OP & 2 & High OP \\
\hline Low INV & 0.61 & 1.18 & 0.43 & Low INV & 1.51 & 2.06 & 0.59 \\
\hline 2 & 0.81 & 1.43 & 1.52 & 2 & 2.77 & 4.05 & 3.78 \\
\hline $\begin{array}{l}\text { High } \\
\text { INV }\end{array}$ & 0.47 & 0.95 & 0.95 & $\begin{array}{l}\text { High } \\
\text { INV }\end{array}$ & 0.26 & 1.94 & 0.61 \\
\hline \multicolumn{8}{|l|}{$\overline{\text { Big }}$} \\
\hline & Low OP & 2 & High OP & & Low OP & 2 & High OP \\
\hline Low INV & 0.76 & 1.42 & 0.90 & Low INV & 1.97 & 3.93 & 2.14 \\
\hline 2 & 0.94 & 1.05 & 0.96 & 2 & 2.13 & 2.65 & 2.29 \\
\hline $\begin{array}{l}\text { High } \\
\text { INV }\end{array}$ & 0.47 & 0.68 & 0.82 & $\begin{array}{l}\text { High } \\
\text { INV }\end{array}$ & 0.99 & 1.61 & 1.96 \\
\hline
\end{tabular}




\section{References}

Artmann, S., P. Finter, A. Kempf, S. Koch, and E. Theissen. 2012. The cross-section of German stock returns: new data and new evidence. Schmalenbach Business Review 64:20-43.

Ball, R., J. Gerakos, J. Linnainmaa, and V. Nikolaev. 2015. Deflating profitability. Journal of Financial Economics 117:225-248.

Banz, R.W. 1981. The relationship between return and market value of common stocks. Journal of Financial Economics 9(1):3-18.

Brueckner, R., P. Lehmann, M. Schmidt, and R. Stehle. 2015. Non-U.S. multi-factor data sets should be used with caution. Working Paper, Humboldt University Berlin.

Brueckner, R., P. Lehmann, M. Schmidt, and R. Stehle. 2015. Another German Fama/French factor data sets. Working Paper, Humboldt University Berlin.

Carhart, M. 1997. On persistence in mutual fund performance. Journal of Finance 52(1):57-82.

Chiah, M., D. Chai, A. Zhong, and S. Li. 2016. A better model? An empirical investigation of the FamaFrench five factor model in Australia. International Review of Finance 16:595-638.

Cooper, M., H. Gulen, and M. Schill. 2008. Asset growth and the cross-section of stock returns. The Journal of Finance 63:1609-1651.

Daniel, K., S. Titman, and K.C.J. Wei. 2001. Explaining the cross-section of stock returns in Japan: factors or characteristics? The Journal of Finance 56(2):743-766.

Fama, E.F., and K.R. French. 1993. Common risk factors in the returns on stocks and bonds. Journal of Financial Economics 33:3-56.

Fama, E.F., and K.R. French. 2012. Size, value, and momentum in international stock returns. Journal of Financial Economics 105:457-472.

Fama, E.F., and K.R. French. 2015. A five-factor asset pricing model. Journal of Financial Economics $116: 1-22$.

Fama, E.F., and K.R. French. 2017. International tests of a five-factor asset pricing model. Journal of Financial Economics 123:441-463.

Fama, E.F., and K.R. French. 2018. Choosing factors. Journal of Financial Economics 128:234-252.

Gibbons, R., T. Ross, and J. Shanken. 1989. A test of the efficiency of a given portfolio. Econometrica 57(2):1121-1152.

Glaser, M., and M. Weber. 2003. Momentum and turnover: evidence from the German stock market. Schmalenbach Business Review 55(2):108-135.

Griffin, J.M. 2002. Are the Fama and French factors global or country specific? The Review of Financial Studies 15(3):783-803.

Hanauer, M. X., C. Kaserer, and M. S. Rapp. 2011. Risikofaktoren und Multifaktormodelle fuer den Deutschen Aktienmarkt (Risk Factors and Multi-Factor Models for the German Stock Market). CEFS Working Paper Series, No. 2011-01.

Harvey, C.R., Y. Liu, and H. Zhu. 2016. and the cross-section of expected returns. The Review of Financial Studies 29(1):5-68.

Hou, K., C. Xue, and L. Zhang. 2015. Digesting anomalies: an investment approach. The Review of Financial Studies 28:650-705.

Huberman, G., and S. Kandel. 2015. Mean-variance spanning. The Journal of Finance 42:873-888.

Huynh, T. 2018. Explaining anomalies in Australia with a five factor asset pricing model. International Review of Finance 18:123-135.

Kubota, K., and H. Takehara. 2018. Does the Fama and French five-factor model work well in Japan? International Review of Finance 18:137-146.

L'Her, J.-F., T. Masmoudi, and J.-M. Suret. 2004. Evidence to support the four-factor pricing model from the Canadian stock market. Journal of International Financial Markets, Institutions and Money 14(4):313-328.

Miller, M., and F. Modigliani. 1961. Dividend policy, growth, and the valuation of shares. The Journal of Business 34:411-433.

Novy-Marx, R. 2013. The other side of value: the Gross Profitability Premium. Journal of Financial Economics 108:1-28.

Schmidt, P.S., U. von Arx, A. Schrimpf, A. Wagner, and A. Ziegler. 2019. Common Risk Factors in International Stock Markets. Financial Markets and Portfolio Management, 33(3):213-241.

Schrimpf, A., M. Schroeder, and R. Stehle. 2007. Cross-sectional tests of conditional asset pricing models: evidence from the German stock market. European Financial Management 13:880-907. 
Walkshaeusl, C., and S. Lobe. 2014. A reexamination of the issuance and investment anomalies in international markets. Schmalenbach Business Review 66:245-275.

Ziegler, A., M. Schroeder, A. Schulz, and R. Stehle. 2007. Multifaktormodelle zur Erklaerung deutscher Aktienrenditen: Eine empirische Analyse. Schmalenbach Business Review 59:355-389.

Publisher's Note Springer Nature remains neutral with regard to jurisdictional claims in published maps and institutional affiliations. 